\title{
Quality of life in elderly subjects with a diagnostic label of asthma from general practice registers
}

\author{
C.A.E. Dyer*, S.L. Hill ${ }^{+}$, R.A. Stockley ${ }^{+}$, A.J. Sinclair*
}

Quality of life in elderly subjects with a diagnostic label of asthma from general practice registers. C.A.E. Dyer, S.L. Hill, R.A. Stockley, A.J. Sinclair. (C)ERS Journals Ltd 1999. ABSTRACT: The aim of this study was to assess health-related quality of life (QoL) in elderly subjects with a diagnostic label of asthma from a general practice population, and to determine the main contributory factors.

Sixty people aged $\geq 70$ yrs with a primary care diagnostic label of asthma, and 43 control subjects were recruited. Assessment of bronchodilator response, and oral steroid trials were conducted where possible. The main outcome measures were QoL scores for the Short Form (SF)-36 and the St George's Respiratory Questionnaire (SGRQ).

In the asthma group, 29 subjects demonstrated a significant airway response to bronchodilators or steroids. Mean SF-36 scores were significantly worse in the total asthma group for components of physical function, physical role limitation, and general health, although psychological scores were similar. QoL remained worse than controls in those subjects with a significant bronchodilator response. Dyspnoea and depression accounted for $61 \%$ of the variance in the SGRQ, but forced expiratory volume in one second was not an independent variable.

Quality of life is impaired in elderly people with a diagnosis of asthma, including those with demonstrable airway variability. Many older subjects with asthma note a variety of symptoms, highlighting the need for further research into the adequacy and efficacy of their treatment.

Eur Respir J 1999; 14: 39-45.

Asthma in younger subjects and chronic obstructive pulmonary disease (COPD) in subjects of all ages are recognized to be causes of a reduced quality of life $(\mathrm{QoL})$ [1-3], but there is little information relating to asthma and its effect on QoL in older adults. A literature search on Medline between 1986 and 1997, using the keywords "asthma", "aged" and "QoL" detected only 37 articles, most of which were questionnaire validation studies including very small numbers of older people. Although asthma is a common chronic condition in elderly people $[4,5]$, without more information regarding its impact, it is unlikely to become a priority for research initiatives or for developing comprehensive therapeutic strategies to tackle it. The results of a study, recently published by the authors of hospitalized elderly patients with asthma just prior to discharge, showed that they had a relatively poor QoL compared with age- and sex-matched hospital control subjects [6]. However, as most asthma care takes place in general practice, it would be pertinent to examine the impact of asthma in this setting.

There are a number of factors which might lead to a reduced QoL in lung diseases, and although breathlessness might be the initiating impairment leading to disability and reduced life quality, a number of secondary features may develop [7]. Such examples could include depression and muscle wasting, which would require alternative strategies to tackle them. These factors may be of particular relevance to elderly people as they are more likely to have multiple pathology and be frail or socially isolated.
*Dept of Geriatric Medicine \& Gerontology, University of Birmingham, UK. ${ }^{+}$Dept of Respiratory Medicine, University Hospital Birmingham NHS Trust, UK.

Correspondence: C.A.E. Dyer

The Hayward Building

Selly Oak Hospital

Raddlebarn Road

Selly Oak

Birmingham B17 6JD

UK

Fax: 441216278304

Keywords: Asthma

depression

elderly

quality of life

Received: July 231998

Accepted after revision February 151999
Therefore the aim of the current study was to assess QoL in elderly subjects with a general practice diagnostic label of asthma compared with control subjects. In addition, the effect of contributory factors such as functional status, depression, dyspnoea and baseline lung function, on QoL was analysed. In view of the difficulties surrounding the diagnosis of asthma, it was also decided to separately analyse subjects with physiological evidence of a bronchodilator or steroid response.

\section{Methods}

\section{Study subjects and collection of data}

This cross-sectional case-control study was conducted in several suburban areas around the City of Birmingham, UK. Five general practices agreed to participate, and provided access to their computerized records. One hundred and thirty-nine people aged $\geq 70$ yrs who had a diagnostic label of asthma were identified. Twenty-seven subjects were excluded for a variety of reasons: terminal illness (6), dementia or a Mini-Mental State Examination (MMSE) score of $\leq 15$ (1), institutionalization (6), known bronchiectasis, pulmonary fibrosis or previous lung surgery (5), or a known contra-indication to steroid therapy (diabetes or active peptic ulcer) (9). The remaining 112 subjects were contacted in writing and invited to participate in the study, with two follow-up letters and a telephone call for 
nonresponders. Fifty subjects could not be contacted or refused to participate, and two agreed but died before assessment. The remaining 60 subjects (overall response rate $54 \%$ ) were assessed at home and subsequently at the study centre as described below.

Control subjects were selected blind to the investigators (usually by the practice manager), using the next person of the same age and sex on the practice list to a participating subject with asthma. Subjects were excluded as above and 43 agreed to participate (response rate $45 \%$ ). All patients gave written informed consent and the study was approved by the local Research Ethics Committee.

\section{Assessment scales}

The MMSE of FolsteIn et al. [8] was used to assess cognition, and a modified Barthel index [9] was used to assess basic physical function. The Medical Research Council (MRC) questionnaire on Respiratory Symptoms [10] was used to document symptoms, and the 15-item Geriatric Depression Score (GDS15) to assess depressive symptoms, which has been shown recently to correlate well with the 30 -item scale (a score of $\geq 5$ is suggestive of depression) [11]. Comorbidity (number of major medical problems) was identified by a questionnaire detailing the presence of heart problems, stroke illness, arthritis or other major ongoing medical problems, supplemented by general practice records. QoL was evaluated by the generic Short Form (SF)-36 health survey questionnaire [12] which is divided into eight different domains (plus one relating to change in health), each with a maximum score of 100 denoting "best" QoL. The SF-36 has been used in previous studies of patients with chronic airflow obstruction and asthma [13,14], and has been shown to be suitable for use in elderly subjects [15]. The diseasespecific St George's Respiratory Questionnaire (SGRQ) [16], which is divided into "symptoms", "activities" and "impact" sections, each with a maximum (worst) score of 100 , was also used. Self-completion was encouraged wherever possible, although a standardized interview was conducted if necessary.

\section{Lung investigations}

Subjects were invited to the Lung Investigation Unit and requested to refrain from taking caffeine-containing drinks and inhaled bronchodilators on the day of testing. Attendance was deferred for 6 weeks following an upper respiratory tract infection or exacerbation of wheezing. Spirometry (wedge bellows, Vitalograph, Buckinghamshire, UK) was performed by C.A.E. Dyer according to national criteria [17]. In addition, static lung volumes (helium dilution technique) and the single-breath transfer factor of the lung for carbon monoxide $(T \mathrm{~L}, \mathrm{CO})$ test were performed, and corrected for alveolar ventilation to obtain the carbon monoxide transfer coefficient $(K C O)$. Spirometry was repeated $30 \mathrm{~min}$ after combined nebulized salbutamol $5 \mathrm{mg}$ and ipratropium bromide $0.5 \mathrm{mg}$. If post-nebulizer forced expiratory volume in one second (FEV1) was $<85 \%$ of predicted (reference values taken from QUANJER [18]) the subjects with asthma were asked to take prednisolone $20 \mathrm{mg} \cdot$ day $^{-1}$ for 14 days followed by repeat spirometry. Airway reversibility was defined as at least $15 \%$ improvement in FEV1 (minimum $200 \mathrm{~mL}$ ) or forced vital capacity (FVC) (minimum $300 \mathrm{~mL}$ ) $30 \mathrm{~min}$ after bronchodilators or following the oral steroid trial.

\section{Statistical analysis}

Data were analysed using SPSS version 6.0 (SPSS, Chicago, IL, USA). Independent sample Student's t-tests were used to compare data relating to QoL, and the MannWhitney U-test where data were not normally distributed. Single correlations were assessed using Pearson's coefficient or Spearman's test where indicated. Multiple regression analyses were performed in a stepwise manner with the SGRQ and then the SF-36 as the dependent variable. Although the SF-36 has no total score, its eight domains were amalgamated into two categories, "physical" and "mental", for the purposes of this analysis as recommended previously [12]. Various models were evaluated, and the variables assessed included age, sex, functional status (Barthel score), dyspnoea (shortness of breath at own pace, yes or no, according to the MRC Respiratory Symptoms Questionnaire [10]), depression, FEV1 and $K C O$. Comorbidity was also included as a variable in the equation. The asthma and control group data were then combined, and a stepwise multiple regression analysis was performed to determine the independent contribution of the presence of asthma on the SF-36 "physical" category.

A sample size calculation demonstrated that with 60 subjects and 40 control subjects there was over $80 \%$ power to detect a difference between means of 15 points in any of the SF-36 components with a within-group standard deviation of 25 (out of 100). A p-value of $<0.05$ was considered significant. Data for the QoL measures were normally distributed for the asthma group, but not in the control group, with the exception of the SF-36 data.

\section{Results}

\section{Characteristics of population}

Both groups were well matched for age, sex and comorbidities as summarized in table 1 . With the exception of an increased frequency of chronic bronchitis in the asthma group, there was no statistical difference in comorbidity rates between the two groups. Although there were few current smokers, the asthma group had a median 20 pack-yrs smoking history (equivalent to one packet of cigarettes for 20 yrs) compared with only 3 pack-yrs in the control group $(\mathrm{p}=0.02)$. Fifteen subjects reported asthma for $>40$ yrs, with a median value of 12 yrs for the asthma group (range 1-76 yrs), and 17 subjects in the asthma group had coexisting chronic bronchitis, according to MRC criteria. All subjects admitted to having "current symptoms of asthma" and were taking asthma-related medication. Fifty-three subjects with asthma reported wheeze in the past 12 months, 40 reported attacks of shortness of breath with wheeze, and 33 were short of breath walking at their own pace.

In the asthma group, 29 had reversible airflow obstruction (as determined above), and the mean age of this subgroup (77 yrs range 70-91) was similar to asthma subjects with no reversibility ( 75 yrs, range $70-89$ ). 
Table 1. - Characteristics and comorbidity of study population

\begin{tabular}{lcc}
\hline & Asthma group & Control group \\
\hline Subjects & 60 & 43 \\
Age yrs & $77(70-91)$ & $76(70-89)$ \\
Female & 33 & 23 \\
Living alone & 22 & 15 \\
Smoking history & & \\
Current smokers & 9 & 6 \\
Exsmokers & 41 & 23 \\
$\quad$ Lifetime nonsmokers & 10 & 15 \\
Comorbidity & & 3 \\
Chronic bronchitis & 17 & 8 \\
Heart disease & 15 & 2 \\
Stroke & 5 & 21 \\
Arthritis & 31 & 7 \\
Depression history & 8 & \\
Other comorbidity & 13 & $29(23-30)$ \\
Functional status & & $20(16-20)$ \\
$\quad$ Median MMSE & $28(19-30)$ & \\
Median Barthel score & $20(16-20)$ & \\
\hline
\end{tabular}

Data are presented as numbers with ranges in parentheses. MMSE: Mini-Mental State Examination. ${ }^{+}: \mathrm{p}=0.02$. No significant differences were found between the groups for any of the other categories listed above.

\section{Lung function data}

In the asthma group 16 subjects were unable to perform spirometry (three had a prolonged illness after initial questionnaire visit, six refused the tests, and seven were unable to meet the criteria for acceptable spirometry). Of the remaining 44 subjects, 28 had a post-nebulizer FEV1 of $<85 \%$ pred, and the average post-FEV1 of the whole group was $1.3 \pm 0.1 \mathrm{~L}$. The mean increase in FEV1 after bronchodilators was $23.4 \%$, but in only 21 cases was this a significant rise as defined above, from a mean of $1.1 \pm 0.1 \mathrm{~L}$ to $1.47 \pm 0.1 \mathrm{~L}$. Only 13 subjects (out of 28 eligible) com- pleted the oral steroid trial, and five showed an increase in FEV1 $>15 \%$ and $200 \mathrm{~mL}$ (FEV1 pretherapy $=0.70 \pm 0.04 \mathrm{~L}$ rising to $1.1 \pm 0.07 \mathrm{~L}$ post-therapy) although four had already shown a significant bronchodilator response. In the remaining eight subjects the FEV1 did not change from the pre-steroid value of $0.8 \pm 0.1 \mathrm{~L}$. It is of note that only eight (18\%) out of 44 subjects with asthma who were able to perform lung function tests had an FEV1 $<85 \%$ pred and no demonstrable bronchodilator or steroid response.

The average lung function for the control group was close to the predicted values for their age and height (table 2 ). As expected there was no change in FEV1, FVC or FEV1/FVC ratio following bronchodilators. Only two control subjects had an FEV1 $<85 \%$ pred (minimum $74.2 \%$ ) and neither had any respiratory symptoms. In addition only one control subject had a significant increase in FEV1 following bronchodilators, but again this was not associated with any baseline symptoms.

\section{Quality-of-life data}

Several domains of the SF-36 indicate significantly impaired QoL in the asthma group compared with the control group, namely the physical, physical role limitation, general health perception, and social components (table 3 ), but most subjects felt that their health was unchanged over the last 12 months. The mental, mental role limitation, energy and pain components were not different between the groups. The mean scores for all components of the SGRQ were high in the asthma group, being 55.2 for "symptoms", 47.3 for "activities", 25.9 for "impacts", and a mean total score of 35.8. SGRQ results were predictably at floor values for control subjects in each category.

The results for the SF-36 components for those with definite bronchodilator or steroid airway reversibility $(n=$ 29) are shown in table 4. The mean FEV1 in this group

Table 2. - Lung function data for those subjects able to perform spirometry

\begin{tabular}{|c|c|c|c|}
\hline & Asthma group $(n=44)$ & Control group $(n=34)$ & p-value* \\
\hline \multicolumn{4}{|l|}{ FEV1 L } \\
\hline Pre-nebulizer & $1.1 \pm 0.1(60 \pm 2.8)$ & $2.1 \pm 0.1(100 \pm 3.4)$ & $<0.001$ \\
\hline Post-nebulizer & $1.3 \pm 0.1(71 \pm 3.7)$ & $2.1 \pm 0.6(104 \pm 3.6)$ & $<0.001$ \\
\hline Change & $0.2(23.3)$ & $0.07(3.5)$ & $<0.001$ \\
\hline \multicolumn{4}{|l|}{ FVC L } \\
\hline Pre-nebulizer & $1.9 \pm 0.1(80 \pm 3.3)$ & $2.9 \pm 0.1(107 \pm 3.3)$ & $<0.001$ \\
\hline Post-nebulizer & $2.3 \pm 0.1(95 \pm 3.3)$ & $2.9 \pm 0.1(109 \pm 3.5)$ & $<0.001$ \\
\hline Change & $0.4(23.4)$ & $0.04(1.2)$ & $<0.001$ \\
\hline \multicolumn{4}{|l|}{ FEV1/FVC } \\
\hline Pre-nebulizer & $57.6 \pm 2.0$ & $72.3 \pm 1.2$ & $<0.001$ \\
\hline Post-nebulizer & $59.1 \pm 3.6$ & $74.5 \pm 1.3$ & $<0.001$ \\
\hline \multicolumn{4}{|l|}{$\mathrm{PEF} \mathrm{L} \cdot \mathrm{s}^{-1}$} \\
\hline Pre-nebulizer & $3.6 \pm 1.6(65 \pm 4.8)$ & $6.4 \pm 0.8(102 \pm 3.5)$ & $<0.001$ \\
\hline \multirow{2}{*}{\multicolumn{4}{|c|}{$T \mathrm{~L}, \mathrm{CO} \mathrm{mmol} \cdot \mathrm{min}^{-1} \cdot \mathrm{kPa}^{-1}$}} \\
\hline & & & \\
\hline \multirow{2}{*}{\multicolumn{4}{|c|}{ KCO $\mathrm{mmol} \cdot \mathrm{min}^{-1} \cdot \mathrm{kPa} \cdot \mathrm{L}^{-1}$}} \\
\hline & & & \\
\hline Pre-nebulizer & $1.5 \pm 0.1(84 \pm 3.5)$ & $1.6 \pm 0.1(93 \pm 3.1)$ & 0.3 \\
\hline \multicolumn{4}{|l|}{ FRC L } \\
\hline Pre-nebulizer & $3.2 \pm 0.1(108 \pm 4.6)$ & $3.0 \pm 0.1(95 \pm 4.2)$ & 0.2 \\
\hline
\end{tabular}

Data are presented as mean \pm SEM with percentage predicted for age and height shown in parentheses. *: independent sample Student's ttests. FEV1: forced expiratory volume in one second; FVC: forced vital capacity; PEF: peak expiratory flow; $T$ L, CO: transfer factor of the lung for carbon monoxide; KCO: carbon monoxide transfer coefficient; FRC: functional residual capacity. 
Table 3. - Results for all components of the Short-Form (SF)-36 questionnaire

\begin{tabular}{|c|c|c|c|c|c|}
\hline SF-36 components & Asthma group & Control group & Mean difference & $95 \% \mathrm{CI}$ & p-value \\
\hline Physical & $41.8 \pm 26$ & $67.1 \pm 26$ & 25.2 & $14.8-35.7$ & 0.0001 \\
\hline Physical role limitation & $58.7 \pm 37$ & $79.6 \pm 30$ & 20.9 & $7.2-34.6$ & 0.003 \\
\hline Mental role limitation & $82.2 \pm 32$ & $92.2 \pm 21$ & 10.0 & $-1.7-21.2$ & 0.07 \\
\hline Social & $80.9 \pm 24$ & $90.7 \pm 20$ & 9.8 & $0.8-18.7$ & 0.03 \\
\hline Mental & $76.2 \pm 15$ & $77.1 \pm 20$ & 0.9 & $-7.8-6.0$ & 0.80 \\
\hline Energy & $51.5 \pm 20$ & $59.6 \pm 22$ & 8.1 & $-0.3-16.5$ & 0.06 \\
\hline Pain & $75.3 \pm 28$ & $76.2 \pm 25$ & 0.9 & $-11.4-9.5$ & 0.86 \\
\hline Change in health & $43.7 \pm 19$ & $48.8 \pm 16$ & 5.1 & $-2.1-12.3$ & 0.16 \\
\hline General health perception & $53.5 \pm 21$ & $69.8 \pm 16$ & 16.3 & $8.7-23.9$ & 0.0001 \\
\hline
\end{tabular}

Values are presented as mean \pm SD. CI: confidence interval. Independent sample Student's t-tests were used.

was $1.1 \pm 0.1 \mathrm{~L}(52.6 \%)$ prebronchodilator, rising to $1.3 \pm$ $0.1 \mathrm{~L}(67.4 \%)$ postbronchodilator. Mean KCO was $1.49 \pm$ $0.1 \mathrm{mmol} \cdot \mathrm{min}^{-1} \cdot \mathrm{kPa}^{-1} \cdot \mathrm{L}^{-1}(83.5 \%)$, being $<80 \%$ pred in nine subjects.

\section{Depression}

Depressive symptoms were more common in the asthma group compared with the control group. Median GDS15 was 3.0 (interquartile range 2-4) for the asthma group compared with $1(0-2)$ for the control group, $\mathrm{p}<0.001$ (Mann-Whitney U-test). Thirteen (21.7\%) of the asthma group had a GDS15 score of at least 5, indicating probable pathological depression, compared with $5(11.6 \%)$ in the control group $(\mathrm{p}=0.09)$.

\section{Factors influencing quality of life}

In the asthma subjects, using Pearson's correlation coefficient, prebronchodilator FEV1 was inversely associated with SGRQ ( $r=-0.39, \mathrm{p}=0.011)$. KCO was also associated with SGRQ ( $\mathrm{r}=-0.46, \mathrm{p}<0.01)$, as was GDS15 ( $\mathrm{r}=0.64$, $\mathrm{p}<0.001$ ), but not FVC or age. Stepwise multiple regression analysis demonstrated that only dyspnoea and de-

Table 4. - Results for all components of the Short-Form (SF)-36 questionnaire for those subjects with definite bronchodilator reversibility only $(n=29)$ compared with control subjects

\begin{tabular}{lcccc}
\hline SF-36 components & $\begin{array}{c}\text { Asthma } \\
\text { group } \\
(\mathrm{n}=29)\end{array}$ & $\begin{array}{c}\text { Control } \\
\text { group } \\
(\mathrm{n}=43)\end{array}$ & $\begin{array}{c}\text { Mean } \\
\text { difference }\end{array}$ & p-value \\
\hline $\begin{array}{l}\text { Physical } \\
\text { Physical role }\end{array}$ & $38.8 \pm 26$ & $67.1 \pm 26$ & 28.3 & 0.0001 \\
$\quad$ limitation & $50.9 \pm 20$ & $79.6 \pm 30$ & 28.8 & 0.001 \\
$\begin{array}{l}\text { Mental role } \\
\text { limitation }\end{array}$ & $82.7 \pm 31$ & $92.2 \pm 21$ & 9.5 & 0.13 \\
$\begin{array}{l}\text { Social } \\
\text { Mental }\end{array}$ & $80.4 \pm 25$ & $90.7 \pm 20$ & 10.2 & 0.06 \\
$\begin{array}{l}\text { Energy } \\
\text { Pain }\end{array}$ & $44.7 \pm 17$ & $77.1 \pm 20$ & 2.3 & 0.61 \\
$\begin{array}{l}\text { Change in health } \\
\text { General health }\end{array}$ & $43.3 \pm 22$ & $59.6 \pm 22$ & 9.8 & 0.07 \\
perception & $49.5 \pm 19$ & $48.8 \pm 16$ & 2.8 & 0.66 \\
\hline
\end{tabular}

Values are presented as means \pm SD. Independent sample Student's t-tests were used. Airway reversibility is defined as $\geq 15 \%$ increase in forced expiratory volume in one second (minimum $200 \mathrm{~mL}$ ) or forced vital capacity (minimum $300 \mathrm{~mL}$ ) following bronchodilators or the oral steroid trial. pression were independently associated with SGRQ, but not FEV1 (table 5). Dyspnoea combined with GDS15 accounted for $61 \%$ of the variance of the SGRQ. Similar but weaker associations were seen with the SF-36 "Physical" category, although FEV1 did have a small independent effect on QoL using this measure. Age, sex, Barthel score, FVC, KCO and the presence of chronic bronchitis were not independent factors in the determination of the SGRQ or SF-36 "Physical" category. Similarly comorbidity was not an independent variable nor was it correlat-ed with SGRQ ( $\mathrm{r}=0.22, \mathrm{p}=0.09$, Spearman's test). Only GDS15 was significantly associated with the "Mental" category of the SF-36 in the asthma subjects $(r=-0.57$, $\mathrm{p}<0.001)$.

Single correlations and a stepwise multiple regression analysis was performed on the combined data of both groups, using the SF-36 "Physical" category as the dependent variable. The presence of asthma (yes or no) was associated with this category $(r=0.38, p<0.001)$ but this was mainly accounted for by the variation in dyspnoea. Although comorbidity was also associated with QoL singularly ( $\mathrm{r}=0.31, \mathrm{p}=0.001)$, only dyspnoea and GDS 15 were independent factors, accounting, for $38 \%$ of the variation of QoL in the whole group.

\section{Discussion}

This study has demonstrated that QoL is impaired in elderly subjects with a diagnostic label of asthma in

Table 5. - Results of a stepwise multiple regression analysis in the asthma group with St George's Respiratory Questionnaire (SGRQ) and Short Form (SF)-36 "Physical" component as dependent variables

\begin{tabular}{lcccc}
\hline & CumulativeR $^{2}$ & B & SEM & p-value \\
\hline SGRQ & & & & \\
$\quad$ Dyspnoea & 0.41 & -15.4 & 4.4 & 0.001 \\
GDS & 0.61 & 2.9 & 0.7 & 0.001 \\
FEV1 (pre) L & 0.63 & -5.5 & 3.8 & 0.15 \\
$\quad$ Comorbidity & 0.65 & 2.3 & 2.2 & 0.30 \\
SF-36 (Physical) & & & & \\
$\quad$ Dyspnoea & 0.25 & 12.4 & 6.2 & 0.05 \\
GDS & 0.41 & -2.8 & 1.0 & 0.01 \\
FEV1 (pre) L & 0.49 & 14.7 & 5.3 & 0.01 \\
Comorbidity & 0.52 & -4.3 & 2.9 & 0.14 \\
\hline
\end{tabular}

FEV1 (pre): forced expiratory volume in one second prebronchodilator; B: regression coefficient; Dyspnoea categorical variable (shortness of breath at own pace; yes or no); GDS: Geriatric Depression Score. 
primary care, including those with definite physiological evidence of airway hyperresponsiveness. The fact that the SF-36 is able to distinguish between elderly patients with asthma and control subjects, who also have comorbidity, supports its role as a potential outcome measure, as proposed recently by HARPER et al. [19]. Variation in SF-36 score was only weakly related to baseline FEV1, which is consistent with the results described in other studies of patients with COPD [1, 16, 20, 21]. Dyspnoea was, however, significantly and independently associated with QoL, and together with depression accounted for $61 \%$ of the variance in the disease-specific SGRQ. Values of the SGRQ "symptoms" and "activities" sections were the most adversely affected, suggesting that breathlessness and exercise limitation are important factors in reduced life quality in this group. NeJJARI et al. [22] also found that dyspnoea was the major factor in determining "functional status" in a large cohort of elderly people taking antiasthma medication, compared with control subjects. However, QoL itself was not assessed in that study, nor was there any attempt to distinguish subjects with reversible and irreversible airways disease.

The present study evaluated QoL using both a generic and a disease-specific instrument. Generic questionnaires, such as the SF-36, provide a "broad band" approach to assessing health status, and may be of particular importance in an elderly population where comorbidity is greater [23]. The use of such questionnaires is vital when comparing one disease group with another or when comparing the index group with control subjects. In the current study comorbidity (although associated) was not found to be a significant independent determinant of QoL in elderly subjects with asthma, according to the SF-36 or the SGRQ. Comorbidity does, however, have an effect on QoL scores in general populations, while in diseased groups its impact is markedly attenuated by the problems associated with the index condition $[12,24]$. Although it is methodologically difficult to assess SF-36 results in studies across a wide range of conditions, some differences are apparent when compared with respiratory disease in elderly people. In a questionnaire study of patients with Parkinson's disease, for example, poor functional status and self-perceived social stigma had the greatest impact on SF-36 scores [25]. Disability and depression were shown to be predictors of QoL after stroke [26], while disability and pain account for some of the variation in QoL in people with osteoarthritis [23]. By contrast, chronic respiratory disease in older people has been labelled a "hidden disability"; it is not detected by the usual basic functional scales (such as the Barthel score used here) because patients can generally perform their own self-care, although it can often take them many hours to do so because of their dyspnoea [27]. Therefore, it is not surprising that symptoms have a major impact on QoL in lung disease, although much of the variance in the SGRQ remains unexplained. As in other chronic disease states, depression scores were higher in the asthma group compared with control subjects. This is consistent with the recent findings of YoHANNes et al. [28] who demonstrated a very high prevalence of depression in elderly outpatients with COPD. It is surprising, however, that despite the severity of symptoms described by these elderly people with asthma, there was no significant increase in scores for the psychological domains of the SF-
36 , with the exception of social isolation. Asthma and COPD studies in younger people have found that psychosocial problems do appear to play a significant role $[29,30]$. It is possible that older people, while physically limited, consider their symptoms to be a consequence of the ageing process.

Age was not a significant factor in either the SF-36 or the SGRQ results in this study, although the age range sampled makes it difficult to draw firm conclusions. In the published literature, the influence of age on QoL is far from simple. In a UK validation study of the SF-36 in nearly 2,000 patients aged 16-74 yrs, there was a significant negative age gradient in scores for physical functioning and pain, but not for mental health status [31]. MANGIONE et al. [24] specifically investigated the effect of age on SF-36 scores in over 700 patients undergoing elective surgery, employing multiple regression analysis. Age was highly associated with the SF-36 physical domain only, while scores for mental health and general health perception were similar, when comparing patients aged $\geq 70$ yrs with those $<70$ yrs of age. Studies examining age as a factor in chronic lung disease reveal conflicting results. GUYATT et al. [32] found that older people with COPD reported fewer emotional problems, such as depression, anger and frustration than did younger people, while KeTELAARs et al. [1] found no association with QoL and increasing age. McSweEny et al. [29] reported that age was a significant negative determinant of Sickness Impact Profile scores, although this was in a group with very severe lung function being considered for oxygen therapy. In more recent work validating the asthma QoL questionnaire, JUNIPER et al. [33] found no correlation with age and QoL, although only subjects up to the age of 70 yrs were included. Recent work by RENWICK and CONNOLLY [20], in subjects aged 45-86 yrs found no independent effect of age on the SGRQ in obstructive airways disease, using multiple regression analysis. Therefore, it appears unlikely that age per se is a major independent factor determining QoL in chronic lung disease, consistent with the present results.

A limitation of the present study was the relatively low recruitment rate in both groups, which raises the possibility of selection bias, although the rate is remarkably similar to a recent questionnaire study examining the impact of asthma in people aged 16-50 yrs [34]. However, if such a bias has occurred it is more likely to have excluded the frailer subjects with a poorer QoL [15], which would actually underestimate the impact of QoL on airways disease [35]. It is also possible that frailer control subjects have been under-represented, which may have emphasized the data difference reported here. However, recent regional normative data from a large study of mean SF-36 scores for elderly residents in Dudley, near Birmingham, UK, where only $13 \%$ refused to be interviewed [36], revealed very similar values to the current control group. This suggests that the data reported here is representative of nonasthmatic elderly subjects. Finally, the mean age of nonresponders (77 yrs) in the present study is almost identical to responders. It is therefore concluded that significant selection bias has probably not occurred in the control group, but a possible bias in the asthmatic group may have minimized the differences identified here. This study also illustrates the difficulties of studying asthma in an elderly population identified from primary care 
records. Asthma is defined as an inflammatory disease characterized by widespread airway narrowing, which changes its severity over short periods of time either spontaneously or as a result of treatment, although it is recognized that long-standing asthma can lead to irreversible or only partially reversible airflow obstruction [37]. Unfortunately, there is no "gold standard" enabling asthma to be clearly identified especially in the elderly, where there is known to be a considerable overlap with chronic bronchitis and emphysema [5], as reconfirmed in this study.

In conclusion, older people with a diagnostic label of asthma have an impaired quality of life, and breathlessness and depressive symptoms are major determinants, even after adjustment for baseline forced expiratory volume in one second. This suggests that better control of symptoms and depression might lead to an improvement in the quality of life of these patients. However, further studies including optimal therapeutic intervention would be necessary to clarify this possibility. In addition, it would be of importance to determine the nature of the underlying lung disease in those patients who do not have demonstrable reversibility of airflow obstruction, as this may influence both treatment and prognosis.

\begin{abstract}
Acknowledgements. The authors are particularly grateful to the following general practices for their assistance with this study: The Bournville \& Varsity Practice, Ridgacre Road Practice, Katie Road Health Centre, Weoley Park Road Practice, and the Harborne Medical Centre, and also for the support of the technicians and physiologists at the Lung Investigation Unit, Queen Elizabeth Hospital, Birmingham.
\end{abstract}

\section{References}

1. Ketelaars CAJ, Schlosser MAG, Mostert R, Huyer AbuSaad H, Halfens RJG, Wouters EFM. Determinants of health-related quality of life in patients with chronic obstructive pulmonary disease. Thorax 1996; 51: 39-43.

2. Gibson PG, Henry RL, Vimpani GV, Halliday J. Asthma knowledge, attitudes, and quality of life in adolescents. Arch Dis Childhood 1995; 73: 321-326.

3. Williams SJ. Chronic respiratory illness and disability: a critical review of the psychosocial literature. Soc Sci Med 1989; 28: 791-803.

4. Burr ML, Charles TJ, Roy K, Seaton A. Asthma in the elderly: an epidemiological survey. BMJ 1979; 1: 10411044.

5. Burrows B, Barbee RA, Cline MG, Knudson RJ. Characteristics of asthma among elderly adults in a sample of the general population. Chest 1991; 100: 935-942.

6. Dyer CAE, Sinclair AJ. A hospital-based case-control study of quality of life in older asthmatics. Eur Respir $J$ 1997; 10: 337-341.

7. Jones PW. Quality of life measurement for patients with diseases of the airways. Thorax 1991; 46: 676-682.

8. Folstein MF, Folstein FE, McHugh PR. Mini Mental Status: a practical method for grading cognitive state of patients for the clinician. J Psychiatr Res 1975; 12: 189 198.

9. Mahoney FI, Barthel DW. Functional evaluation of the Barthel index. Maryland State Med J 1965; 14: 61-65.
10. Medical Research Council Questionnaire on Respiratory Symptoms. London, 1986.

11. D'Ath P, Katona P, Mullan E, Evans S, Katona C. Screening, detection, and management of depression in primary care attenders: I: the acceptability and performance of the 15 item Geriatric Depression Scale (GDS15) and the development of shorter versions. Family Practice 1994; 11: 260-266.

12. Ware JE. SF-36 Health Survey Manual and Interpretation Guide. Boston, Nimrod Press, 1995.

13. Mahler DA, Mackowiak JI. Evaluation of the shortform 36-item questionnaire to measure health-related quality of life in patients with COPD. Chest 1995; 107: 1585-1589.

14. Bousquet J, Knani J, Dhivert $\mathrm{H}$, et al. Internal consistency and validity of the SF-36 Questionnaire. Am J Respir Crit Care Med 1994; 148: 371-375.

15. Hayes V, Morris J, Wolfe C, Morgan M. The SF-36 health survey questionnaire: is it suitable for use in older adults? Age Ageing 1995; 24: 120-125.

16. Jones PF, Quirk FH, Baveystock CM, Littlejohns P. A self-complete measure of health status for chronic airflow limitation: the St. George's Respiratory Questionnaire. Am Rev Respir Dis 1992; 145: 1321-1327.

17. ARTP/BTS. Guidelines for the measurement of respiratory function. Respir Med 1994; 88: 165-194.

18. Quanjer PHD. Standardization of lung function tests1993 update. Report of a working party for the European Community for Steel and Coal. Eur Respir J 1993; 6: Suppl. $16,5 \mathrm{~s}-40 \mathrm{~s}$.

19. Harper R, Brazier JE, Waterhouse JC, Walters SJ, Jones NMB, Howard P. Comparison of outcome measures for patients with chronic obstructive pulmonary disease (COPD) in an out-patient setting. Thorax 1997; 52: 879-887.

20. Renwick D, Connolly MJ. Impact of obstructive airways disease on quality of life in older adults. Thorax 1996; 51: 520-525.

21. van Schayck CP, Rutten-van Molken MP, van Doorslaer EK, Folgering $\mathrm{H}$, van Weel C. Two-year bronchodilator treatment in patients with mild airflow obstruction. Contradictory effects on lung function and quality of life. Chest 1992; 102: 1384-1391.

22. Nejjari C, Tessier JF, Barberger-Gateau P, Jacqmin H, Dartigues JF, Salamon R. Functional status of elderly people treated for asthma: a population-based case-control study. Eur Respir J 1994; 7: 1077-1083.

23. Bowling A. Measuring Disease. 1st Edn. Buckingham, Open University Press, 1997.

24. Mangione CM, Marcantonio ER, Goldman L, et al. Influence of age on measurement of health status in patients undergoing elective surgery. $J$ Am Geriat Soc 1993; 41: 377-383.

25. Jenkinson C, Peto V, Fitzpatrick R, Greenhall R, Hyman N. Self-reported functioning and well-being in patients with Parkinson's disease: comparisons of the Short-form Health Survey (SF-36) and the Parkinson's Disease Questionnaire (PDQ-39). Age Ageing 1995; 24: 505-509.

26. King RB. Quality of life after stroke. Stroke 1996; 27: $1467-1472$

27. Connolly MJ. Obstructive airways disease: a hidden disability. Age Ageing 1996; 25: 265-267.

28. Yohannes AM, Roomi J, Baldwin RC, Connolly MJ. Depression in elderly outpatients with disabling chronic obstructive pulmonary disease. Age Ageing 1998; 27 : $155-160$. 
29. McSweeny J, Grant I, Heaton R, Adams K, Timms R. Life quality of patients with COPD. Arch Intern Med 1982; 142: 473-479.

30. Garden GMF, Ayres JG. Psychiatric and social aspects of brittle asthma. Thorax 1993; 48: 501-505.

31. Brazier JE, Harper R, Jones NMB, et al. Validating the SF-36 health survey questionnaire: new outcome measure for primary care. BMJ 1992; 305: 160-164.

32. Guyatt GH, Townsend M, Berman LB, Pugsley SO. Quality of life in patients with chronic airflow limitation. Br J Chest Dis 1987; 81: 45-54.

33. Juniper EF, Guyatt GH, Epstein RS, Ferrie PJ, Jaeschke R, Hiller TK. Evaluation of impairment of health related quality of life in asthma: development of a questionnaire for use in clinical trials. Thorax 1996; 51: 520-525.
34. Marks GB, Burney PGJ, Premaratne UN, Simpson J, Webb J. Asthma. Greenwich, UK: impact of the disease and current management practices. Eur Respir J 1997; 10: $1224-1229$.

35. van den Boom G, Rutten-van Molken MPMH, Tirimanna PRS, van Schayck CP, Folgering $\mathrm{H}$, van Weel $\mathrm{C}$. Association between health-related quality of life and consultation for respiratory symptoms: results from the DIMCA programme. Eur Respir J 1997; 11: 67-72.

36. Lyons RA, Crome P, Monaghan S, Killalea D, Daley JA. Health status and disability among elderly people in three UK districts. Age Ageing 1997; 26: 203-209.

37. Brown PJ, Greville HW, Finucane KE. Asthma and irreversible airflow obstruction. Thorax 1984; 39: 131136. 